\title{
A twenty-four-hour observational study of hand hygiene compliance among health- care workers in Debre Berhan referral hospital, Ethiopia
}

Tufa Kolola* and Takele Gezahegn

\begin{abstract}
Background: Hand hygiene $(\mathrm{HH})$ is recognized as the single most effective strategy for preventing health care-associated infections. In developing countries, data on hand hygiene compliance is available only for few health-care facilities. This study aimed to assess hand hygiene compliance among health-care workers in Debre Berhan referral hospital, Ethiopia.

Methods: This study employed the WHO hand hygiene observation method. Direct observation of the health care workers (HCWs) was conducted using an observation record form in five different wards. Trained and validated observers watched HCWs while they had direct contact with patients or their surroundings, and the observers then recorded all possible hand hygiene opportunities and hand hygiene actions. Observation was conducted over a $24 \mathrm{~h}$ period to minimize selection bias. More than 200 opportunities per ward were observed according to WHO recommendation, except in neonatal intensive care unit. $\mathrm{HH}$ compliance was calculated by dividing the number of times hand hygiene was performed by the total number of opportunities for hand hygiene. A 95\% confidence interval (Cl) was computed for compliance with the exact binomial method.
\end{abstract}

Results: A total of 917 hand hygiene opportunities were observed during the study. Overall HH compliance was 22. 0\% (95\% Cl: 19.4-24.9). HH compliance was similar across all professional categories and did not vary by shift. Levels of compliance were lower before patient contact (2.4\%; 95\% Cl: 0.9-5.3), before an aseptic procedure (3.6\%; 95\% Cl: 1.6-7.6) and after contact with patient surroundings (3.3\%; 95\% Cl: 1.2-7.9), whereas better levels of compliance were found after body fluid exposure (75.8\%; 95\% Cl: 68.0-82.3) and after patient contact (42.8\%; 95\% Cl: 35.2-50.7).

Conclusion: $\mathrm{HH}$ compliance of HCWs was found to be low in Debre Berhan referral hospital. Compliance with indications that protect patients from infection was lower than that protect the HCWs. The findings of this study indicate that $\mathrm{HH}$ compliance needs further improvement.

Keywords: Hand hygiene compliance, Direct observation method, Health-care worker, Debre Berhan, World health organization

\footnotetext{
* Correspondence: tufabest@gmail.com

Department of public health, Debre Berhan University, P.O.Box 445, Debre Berhan, Ethiopia
} 


\section{Background}

Health care-associated infections (HAIs) are a major threat to patient safety worldwide [1-4]. Such infections spread between patients in the health-care settings by various means, mainly via the hands of health-care workers (HCWs) $[5,6]$.

Hand hygiene $(\mathrm{HH})$ is the single most effective strategy for preventing HAIs [7-9]. Hand hygiene is defined as either rubbing the hands with an alcoholbased handrub or handwashing with soap and water [6]. WHO has launched a multimodal hand hygiene improvement strategy to optimize hand hygiene in health care settings [10]. This strategy is now recommended as the most reliable and evidence-based method for ensuring sustainable hand hygiene improvement around the world [11-16]. HCWs compliance with hand hygiene during routine patient care is an integral part of this strategy. $\mathrm{HH}$ compliance is measured in a variety of ways. These include: direct observation, handrub consumption, and survey methods [17, 18]. Direct observation of HCWs using WHO's hand hygiene observation tool is currently recognized as the gold standard for hand hygiene monitoring in the sequence of care [6, 10, 17].

World Health Organization has endorsed "My five moments for hand hygiene" approach, the moments when hand hygiene is required, to effectively interrupt the spread of HAIs [19]. This approach encourages HCWs to clean their hands, i.e., (1) before patient contact, (2) before an aseptic procedure, (3) after body fluid exposure, (4) after patient contact and (5) after contact with patient surroundings [20]. The World Health Organization (WHO) has defined these moments as hand hygiene opportunities (HHOs) to which HCWs should comply with $[10,18]$. Hand hygiene opportunity exists whenever one of the indications for hand hygiene occurs. Each opportunity corresponds to hand hygiene action [18].

In developing countries with high burden of healthcare-associated infections, improving HCWs compliance with hand hygiene during routine patient care is urgently needed for the patient safety $[2,21]$. Despite the clear benefits of hand hygiene practices in healthcare settings, compliance remains an issue in developing countries [11]. In Ethiopia, data on hand hygiene compliance is available only for few health-care facilities [14, 22]. In Debre Berhan referral hospital, HCWs compliance to the WHO's five moments for hand hygiene was not investigated so far. This study aimed to assess hand hygiene compliance among health-care workers in Debre Berhan referral hospital through direct observation of the WHO's five moments. The result of this study provides insights about hand hygiene compliance level of health care providers.

\section{Methods}

\section{Study setting}

A cross-sectional study was conducted in Debre Berhan referral hospital using the WHO hand hygiene observation method. Debre Berhan referral hospital is located in North Shoa Zone of Amhara Region which is about $130 \mathrm{~km}$ away from Addis Ababa to Dessie. Currently, this hospital serves as a referral centre for a population of North Shoa Zone of Amhara region and for other population from the neighbouring regions. The hospital has a total of $307 \mathrm{HCWs:} 38$ physicians, 153 nurses, 26 midwives, 7 anaesthetists, 31 laboratory technicians, 2 physiotherapists, 4 dentists, 6 radiographers, 4 optometrists and 36 pharmacists. In addition, 48 medical interns were affiliated to this hospital during data collection. This study was conducted from May 2 to 9, 2017 in the selected wards (Medical, Surgical, Paediatric, Obstetrics and gynecology, and Neonatal intensive care unit) of the hospital. All HCWs, including medical interns, having direct contact with patients or their surroundings in the selected wards were observed.

\section{Data collection}

Data were collected using standardized WHO's hand hygiene observation tool for direct observation (Additional file 1). Before conducting observation sessions, observers were trained in accordance with the WHO's hand hygiene observation method [23]. Thereafter, observers were validated by one of the authors based on Sax et al.'s [6] recommendation. In the first case, each observer engaged in an observation session during a patient care situation. Each observer completed the observation form separately while observing the same $\mathrm{HCW}$ and the same care sequence. Results were then compared and discordant notifications were discussed. This process was repeated until concordance is reached in terms of the number of hand hygiene opportunities and hand hygiene actions that occurred $[6,20]$.

In brief, three nurses directly watched $261 \mathrm{HCWs}$ having direct contact with patients or their surroundings, and recorded all possible HHOs and HHAs. Observation was conducted over a $24 \mathrm{~h}$ period in each ward to minimize selection bias. The HCWs were unaware of being observed to minimize "Hawthorne effect". Each HCW was observed for a maximum of four HHOs during the observed care sequence. More than 200 opportunities per ward were observed according to WHO recommendation [23], except in neonatal intensive care unit (NICU). Few opportunities were observed in NICU due to the small number of HCWs working in this unit.

\section{Data analysis}

Data analysis was done using Epi Info 7 and SPSS version 21. Data set underlying the findings is available within the 
supplementary information files (Additional file 2). Overall compliance was calculated by dividing the number of times hand hygiene was performed by the total number of opportunities for hand hygiene. We also estimated $\mathrm{HH}$ compliance by professional categories, and "my five moments for hand hygiene". A 95\% confidence interval (CI) was computed for compliance with the exact binomial method. Overlapping 95\% confidence intervals were interpreted as not being significantly different.

\section{Results}

\section{Hand hygiene compliance}

A total of 917 opportunities for hand hygiene were observed during the study. The overall $\mathrm{HH}$ compliance was $22.0 \%$ (95\% CI: 19.4-24.9). HH compliance was 20.6\% (95\% CI:16.2-25.9) for doctors, 22.9\% (95\% CI:19.2-27.0) for nurses, $21.2 \%$ (95\% CI:13.9-30.8) for midwives, and 23.2\% (95\% CI: 13.4-36.7) for other HCWs. HH compliance was slightly higher in the neonatal intensive care unit (NICU) and paediatric ward compared to other wards. $\mathrm{HH}$ compliance varied according to the five moments for hand hygiene. Levels of compliance were lower before patient contact $(2.4 \% \%$; $95 \%$ CI: $0.9-5.3)$, before an aseptic procedure $(3.6 \%$; 95\% CI: $1.6-7.6)$ and after contact with patient surroundings (3.3\%; 95\% CI: 1.2-7.9). Better levels of compliance were found after body fluid exposure (75.8\%; 95\% CI: 68.0-82.3) and after patient contact (42.8\%; 95\% CI: 35.2-50.7) (Table 1).

Hand rubbing was performed in $95,(47.0 \%$; $95 \% \mathrm{CI}$ : 40.2-53.9), out of the 202 hand hygiene actions. Hand rubbing was frequently performed, (55.8\%; 95\% CI: 45.765.5), after patient contact while handwashing with soap and water was more frequent, (76.6\%; 95\% CI: 67.9-83.9), after body fluid exposure compared with other indications (Fig. 1).

\section{Hand hygiene resources}

In this study, sink to patient beds ratio was 1:4.9, and soap was available to $36.4 \%$ of the sinks. Alcohol-based handrub was available for $16.8 \%$ (18/107) of the patient beds.

\section{Discussion}

This study captured hand hygiene compliance of HCWs over a $24 \mathrm{~h}$ period. Overall hand hygiene compliance was low (22\%). HH compliance was low across all professional categories and similar by shift. In line with our study, $\mathrm{HH}$ compliance was found low in previous studies $[14,22,24]$. In low-income and middle-income countries, $\mathrm{HH}$ compliance was averaged $22.4 \%$ before multimodal intervention [11]. Hand hygiene compliance was much lower in the present study compared to post- multimodal intervention studies from India (82\%) [15], Kuwait (61.4\%) [25], and Colombia (77\%) [26].
Table 1 Hand hygiene compliance of HCWs in Debre Berhan Referral Hospital, May 2017

\begin{tabular}{|c|c|c|c|}
\hline Characteristic & $\begin{array}{l}\text { Hand hygiene } \\
\text { opportunities (n) }\end{array}$ & $\begin{array}{l}\text { Hand hygiene } \\
\text { actions }\left(n^{a}\right)\end{array}$ & $\begin{array}{l}\text { Compliance, \% } \\
(95 \% \mathrm{Cl}) \\
\end{array}$ \\
\hline Over all & 917 & 202 & $22.0(19.4-24.9)$ \\
\hline \multicolumn{4}{|c|}{ Professional category } \\
\hline Doctor & 286 & 59 & $20.6(16.2-25.9)$ \\
\hline Nurse & 476 & 109 & $22.9(19.2-27.0)$ \\
\hline Midwife & 99 & 21 & $21.2(13.9-30.8)$ \\
\hline Other HCWs & 56 & 13 & $23.2(13.4-36.7)$ \\
\hline \multicolumn{4}{|l|}{ Ward } \\
\hline Medical & 207 & 44 & $21.2(16.0-27.6)$ \\
\hline Surgical & 203 & 38 & $18.7(13.7-24.9)$ \\
\hline Paediatric & 211 & 56 & $26.5(20.8-33.1)$ \\
\hline OB/GYN & 219 & 43 & $19.6(14.7-25.7)$ \\
\hline $\mathrm{NICU}$ & 77 & 21 & $27.3(18.0-38.8)$ \\
\hline \multicolumn{4}{|l|}{ Shift } \\
\hline Morning & 369 & 86 & $23.3(19.2-28.0)$ \\
\hline After noon & 318 & 74 & $23.3(18.8-28.4)$ \\
\hline Night & 230 & 52 & $22.6(17.5-28.4)$ \\
\hline \multicolumn{4}{|l|}{ Indications } \\
\hline bef. Pat & 255 & 6 & $2.4(0.9-5.3)$ \\
\hline bef. Asept & 195 & 7 & $3.6(1.6-7.6)$ \\
\hline aft.b.f & 149 & 113 & $75.8(68.0-82.3)$ \\
\hline aft.pat & 166 & 71 & $42.8(35.2-50.7)$ \\
\hline aft.p.surr & 152 & 5 & $3.3(1.2-7.9)$ \\
\hline
\end{tabular}

bef. Pat before patient contact, bef. Asept before an aseptic procedure, aft.b.f after body fluid exposure, aft.pat after patient contact, aft.p.surr after contact with patient surroundings, HCWs Health care workers, $n$ Number of opportunities for hand hygiene, $n^{a}$ Number of positive hand hygiene actions, $\mathrm{Cl}$ Confidence interval, Other HCWs, Laboratory technician, dentist and physiotherapist, NICU Neonatal intensive care unit, OB/GYN, Obstetrics and gynecology

The possible reason for low compliance in our study might be due to the WHO's multimodal $\mathrm{HH}$ improvement strategy which was not implemented. For instance, $\mathrm{HH}$ resources were deficient at the point of patient care. There were no visual reminders for hand hygiene at work place. Similarly, there was lack of $\mathrm{HH}$ monitoring and provision of performance feedback to HCWs. Studies have demonstrated that implementation of a multimodal strategy is globally accepted as best approach to achieve $\mathrm{HH}$ compliance in healthcare settings $[11,27,28]$.

Hand hygiene compliance was inconsistent by the five indications for hand hygiene which might be another reason for low compliance. Lower levels of compliance were witnessed for indications before patient contact, before an aseptic procedure and after contact with patient surroundings. By contrast, compliance with hand hygiene was relatively higher after body fluid exposure 


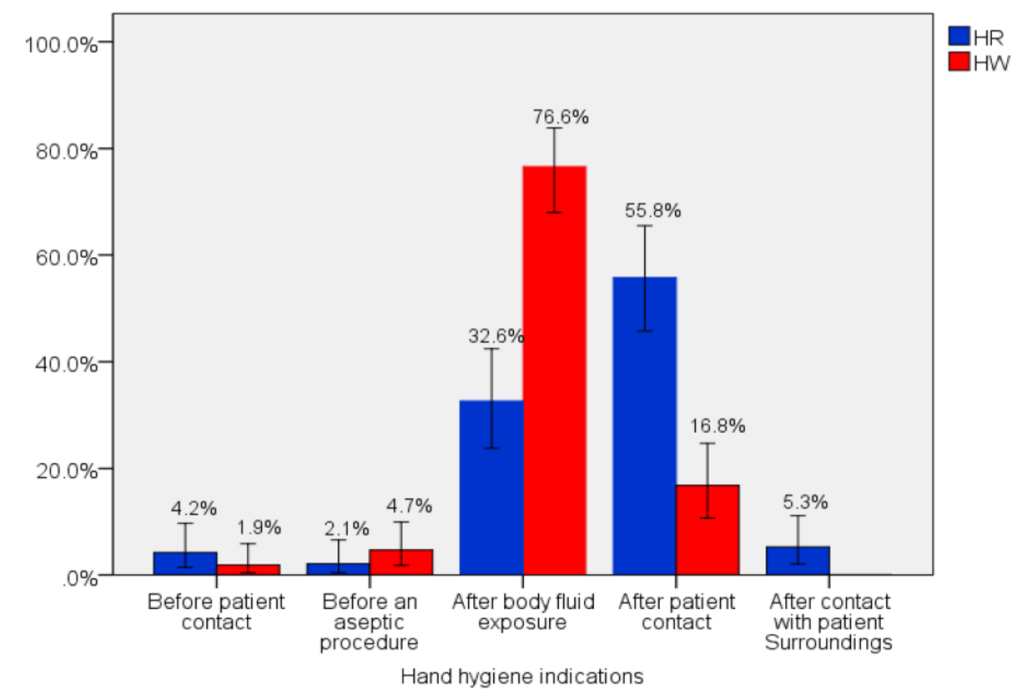

Fig. 1 Hand hygiene actions by indications among HCWs in Debre Berhan Referral Hospital, May 2017. HR: Hand rubbing with an alcohol-based handrub; HW: Handwashing with soap and water; Error bars show 95\% confidence intervals around hand hygiene action; HCWs: Health care workers

followed by after patient contact. This suggests that HCWs more likely to perform $\mathrm{HH}$ for the indications that protect themselves from microbial contamination and infection rather than that protect patients. Selfprotection tendency of HCWs has been identified in multiple studies [11, 25, 29-31].

Hand rubbing is recommended as the gold standard for hand hygiene according to the "my five moments for hand hygiene" in clinical situations [9, 21]. Particularly in resource-constrained settings, the use of alcohol based hand rubs is a practical solution to overcome constraints because they can be distributed individually to staff for pocket carriage and placed at the point of care $[20,21]$. In contrary to findings from other studies $[11,12,32]$, the present study revealed that hand rubbing was not the preferred means for hand hygiene. One reason could be that alcohol based hand rub was deficient at the point of care and was obstacle to performing $\mathrm{HH}$ according to recommendation. Ensuring availability of alcohol-based hand rubs at the point of patient care is a key factor for hand hygiene improvement in previous studies [30,33,34].

The strength of this study is that observation was done over a $24 \mathrm{~h}$ to minimize selection bias. In addition to this, the HCWs were unaware of being observed to minimize "Hawthorne effect". This study was not free of limitations. This study solely employed direct observation method. As a result, did not address why $\mathrm{HH}$ compliance was found to be low. The cross-sectional results of this study might not be representative of $\mathrm{HH}$ compliance throughout the year. This study conducted in a single hospital, and hence the generalizability of our results to other settings might be limited.

\section{Conclusion}

This study showed that $\mathrm{HH}$ compliance of HCWs was found to be low. Indications that are high risk to the patient have lower compliance. This suggests that the need of $\mathrm{HH}$ compliance improvement strategy is evident. Implementing WHO's multimodal strategy is crucial to improve $\mathrm{HH}$ compliance of HCWs. Access to $\mathrm{HH}$ resources should be emphasised as an integral part of $\mathrm{HH}$ improvement strategy.

\section{Additional files}

Additional file 1: Hand hygiene compliance observation form. (DOC $407 \mathrm{~kb})$ Additional file 2: Hand hygiene compliance data set. (SAV $71 \mathrm{~kb})$

\section{Abbreviations}

Cl: Confidence interval; HAl: Health-care associated infection; HCW: Health care worker; $\mathrm{HH}$ : Hand hygiene; HHA: Hand hygiene action; HHO: Hand hygiene opportunity; HR: Hand rubbing; HW: Hand washing; NICU: Neonatal intensive care unit; OB/GYN: Obstetrics and gynecology; PSG: Patient safety goal; WHO: World Health Organization

\section{Acknowledgements}

Not applicable.

\section{Funding}

Not applicable.

\section{Availability of data and materials}

All data generated or analysed during this study are included in this manuscript and its supplementary information files.

\section{Authors' contributions}

TK: conception of the idea, study design, facilitation of data collection, data analysis, drafting the manuscript. TG: study design, facilitation of data collection, revising the manuscript. Both authors read and approved the final manuscript. 


\section{Ethics approval and consent to participate}

This study was approved by the Ethics Review Committee of College of Health Sciences, Debre Berhan University. HCWs were not identified during observation sessions for confidentiality reasons. The need for consent to participate was waived as no data from any individual person was collected in this study.

\section{Consent for publication}

Not applicable.

\section{Competing interests}

The authors declare that they have no competing interests.

\section{Publisher's Note}

Springer Nature remains neutral with regard to jurisdictional claims in published maps and institutional affiliations.

Received: 11 July 2017 Accepted: 25 October 2017

Published online: 30 October 2017

\section{References}

1. World Health Organization (WHO). Report on the burden of endemic health care-associated infection worldwide. Geneva; 2011.

2. Allegranzi B, Nejad SB, Combescure C, Graafmans W, Attar H, Donaldson L, et al. Burden of endemic health-care-associated infection in developing countries: systematic review and meta-analysis. Lancet. 2011;377(9761):228-41.

3. Hearn P, Miliya T, Seng S, Ngoun C, Day NPJ, Lubell Y, et al. Prospective surveillance of healthcare associated infections in a Cambodian pediatric hospital. Antimicrob Resist Infect Control. 2017;6:16.

4. Ahoyo TA, Bankolé HS, Adéoti FM, Gbohoun AA, Assavèdo S, AmoussouGuénou $\mathrm{M}$, et al. Prevalence of nosocomial infections and anti-infective therapy in Benin: results of the first nationwide survey in 2012. Antimicrob Resist Infect Control. 2014;3:17.

5. Kleef Van E, Robotham JV, Jit M, Deeny SR, Edmunds WJ. Modelling the transmission of healthcare associated infections: a systematic review. BMC Infect Dis. 2013;13:294

6. Sax H, Allegranzi B, Chraïti MN, Boyce J, Larson E, Pittet D. The World Health Organization hand hygiene observation method. Am J Infect Control. 2009; 37(10):827-34.

7. Ellingson K, Haas JP, Aiello AE, Kusek L, Maragakis LL, Olmsted RN, et al. Strategies to prevent healthcare-associated infections through hand hygiene. Infect Control. 2014:35(8):937-60.

8. Septimus E, Weinstein RA, Perl TM, Goldmann DA, Yokoe DS. Approaches for preventing healthcare-associated infections: go long or go wide? Infect Control Hosp Epidemiol. 2014;35(7):797-801.

9. Allegranzi B, Pittet D. Role of hand hygiene in healthcare-associated infection prevention. J Hosp Infect. 2009;73(4):305-15.

10. Pittet $D$, Allegranzi B, Boyce J. The World Health Organization guidelines on hand hygiene in health care and their consensus recommendations. Geneva: Infection Control \& Hospital Epidemiology; 2009.

11. Allegranzi B, Gayet-Ageron A, Damani N, Bengaly L, McLaws ML, Moro ML, et al. Global implementation of WHO's multimodal strategy for improvement of hand hygiene: a quasi-experimental study. Lancet Infect Dis. 2013;13(10):843-51.

12. Farhoudi F, Dashti AS, Davani MH, Ghalebi N, Sajadi G, Taghizadeh R. Impact of WHO hand hygiene improvement program implementation: a quasiexperimental trial. Biomed Res Int. 2016:1-7.

13. Allegranzi B, Conway L, Larson E, Pittet D. Status of the implementation of the World Health Organization multimodal hand hygiene strategy in United States of America health care facilities. Am J Infect Control. 2014;42(3):224-30

14. Pfäfflin F, Tufa TB, Getachew M, Nigussie T, Schönfeld A, Häussinger D, et al. Implementation of the $\mathrm{WHO}$ multimodal hand hygiene improvement strategy in a University Hospital in Central Ethiopia. Antimicrob Resist Infect Control. 2017;6:3.

15. Chakravarthy M, Myatra SN, Rosenthal VD, Udwadia FE, Gokul BN, Divatia JV, et al. The impact of the international nosocomial infection control consortium (INICC) multicenter, multidimensional hand hygiene approach in two cities of India. J Infect Public Health. 2015;8(2):177-86.
16. Ho M, Seto W, Wong L, Wong T. Effectiveness of multifaceted hand hygiene interventions in long-term care facilities in Hong Kong: a cluster-randomized controlled trial. Infect Control Hosp Epidemiol. 2012;33(8):761-7.

17. Gould DJ, Drey NS, Creedon S. Routine hand hygiene audit by direct observation: has nemesis arrived? J Hosp Infect. 2011;77(4):290-3.

18. Steed C, Kelly JW, Blackhurst D, Boeker S, Diller T, Alper P, et al. Hospital hand hygiene opportunities: where and when (HOW2)? The HOW2 benchmark study. Am J Infect Control. 2011;39(1):19-26.

19. Sax H, Allegranzi B, Uçkay I, Larson E, Boyce J, Pittet D. "My five moments for hand hygiene": a user-centred design approach to understand, train, monitor and report hand hygiene. J Hosp Infect. 2007:67(1):9-21.

20. World Health Organization. A guide to the implementation $\mathrm{WHO}$ multimodal hand hygiene improvement strategy. Geneva; 2009.

21. Pittet D, Allegranzi B, Storr J, Nejad SB, Dziekan G, Leotsakos A, et al. Infection control as a major World Health Organization priority for developing countries. J Hosp Infect. 2008;68(4):285-92.

22. Schmitz K, Kempker RR, Tenna A, Stenehjem E, Abebe E, Tadesse L, et al. Effectiveness of a multimodal hand hygiene campaign and obstacles to success in Addis Ababa, Ethiopia. Antimicrob Resist Infect Control. 2014;3:8.

23. World Health Organization. Hand hygiene technical reference manual. Geneva; 2009.

24. Abdella NM, Tefera MA, Eredie AE, Landers TF, Malefia YD, Alene KA. Hand hygiene compliance and associated factors among health care providers in Gondar University. BMC Public Health. 2014;14:96.

25. Salama MF, Jamal WY, Al M a, Al-abdulghani KA, Rotimi VO. The effect of hand hygiene compliance on hospital-acquired infections in an ICU setting in a Kuwaiti teaching hospital. J Infect Public Health. 2013;6(1):27-34.

26. Barahona-guzma N, Rojas C, Rodrı M, Olarte N, Villamil-go W, Valderrama A, et al. International journal of infectious diseases impact of the international nosocomial infection control consortium ( INICC ) multidimensional hand hygiene approach in three cities of. Int J Infect Dis. 2014;19:67-73.

27. Storr J, Twyman A, Zingg W, Damani N, Kilpatrick C, Reilly J, et al. Core components for effective infection prevention and control programmes : new WHO evidence-based recommendations. Antimicrob Resist Infect Control. 2017:6:6

28. Reichardt C, Königer D, Bunte-Schönberger K, van der Linden P, Mönch N, Schwab F, et al. Three years of national hand hygiene campaign in Germany: what are the key conclusions for clinical practice? J Hosp Infect. 2013;83(SUPPL. 1):11-6.

29. Wetzker W, Bunte-Schonberger K, Walter J, Pilarski G, Gastmeier P, Reichardt C. Compliance with hand hygiene : reference data from the national hand hygiene campaign in Germany. J Hosp Infect J. 2016;92:328-31.

30. Yawson A, Hesse AA. Hand hygiene practices and resources in a teaching hospital in Ghana. J Infect Dev Ctries. 2013;7(4):338-47.

31. Randle J, Arthur A, Vaughan N. Twenty-four-hour observational study of hospital hand hygiene compliance. J Hosp Infect. 2010;76(3):252-5.

32. Marra AR, Camargo TZS, Cardoso VJ, Moura DF, de Andrade EC, Wentzcovitch J, et al. Hand hygiene compliance in the critical care setting : a comparative study of 2 different alcohol handrub formulations. Am J Infect Control. 2013:41(2):136-9.

33. Allegranzi B, Sax H, Bengaly L, Richet $H$, Minta D, Chraiti M, et al. Successful implementation of the World Health Organization hand hygiene improvement strategy in a referral hospital in Mali, Africa. Infect Control Hosp Epidemiol. 2010;31(2):133-41.

34. Schweon SJ, Edmonds SL, Kirk J, Rowland DY, Carmen A. Effectiveness of a comprehensive hand hygiene program for reduction of infection rates in a long-term care facility. Am J Infect Control. 2013:41(1):39-44. 